\title{
Computational Fluid Dynamic Modeling and Simulation of Red Chili Solar Cabinet Dryer
}

\author{
Eshetu Getahun ${ }^{\mathrm{a}, \mathrm{a}^{*},}$ Maarten Vanierschot ${ }^{\mathrm{b}}$, Nigus Gabbiye ${ }^{\mathrm{a}}$, Mulugeta A. Delele ${ }^{\mathrm{c}}$, Sol- \\ omon Workneh ${ }^{\mathrm{a}}$, Mekonnen Gebreslasie ${ }^{\mathrm{b}}$ \\ ${ }^{\text {a }}$ Faculty of Chemical and Food Engineering, Bahir Dar Technology Institute, Bahir Dar Uni- \\ versity, Ethiopia \\ a* Bahir Dar Energy Center, Bahir Dar Technology Institute, Bahir Dar University, Ethiopia \\ ${ }^{b}$ Mechanical Engineering Technology Cluster TC, Campus Groep T, KU Leuven, A. Vesali- \\ usstraat 13, B3000 Leuven, Belgium \\ ${ }^{c}$ KU Leuven, University of Leuven, Department of Biosystems, MeBioS, De Croylaan 42, \\ 3001 Leuven, Belgium. \\ eshetu201384@gmail.com
}

\begin{abstract}
Red chilies are important sources of nutrients for human diet. It is known that improper handling of the produces causes a significant loss. Drying is a primary and suitable preservation system of chili products before storage to minimize mold/mycotoxin development. This study investigates the potential of solar cabinet chili dryer through rigorous computational fluid dynamic modeling by considering red chili as porous media. The k- $\varepsilon$ turbulence model was utilized to effectively predict the uniformity of drying air velocity, pressure and mass transfer. It was found that the CFD simulation gives accurate prediction of the drying air and velocity and pressure distribution in each tray at inlet air velocity of $1.5 \mathrm{~m} / \mathrm{s}$. The solar absorber temperature was reached up to $54^{\circ} \mathrm{C}$ and the drying chamber temperature was in the range of $34-38^{\circ} \mathrm{C}$. The performance of the dryer was very promising to keep the quality of the dried red chili products.
\end{abstract}

Keywords: Solar cabinet dryer, Red chili, CFD modeling, Moisture transfer.

\section{Introduction}

\subsection{Background}

Chili (Capsicum annum L.) is very significant condiment and cash crop throughout the world. Red chilies are important sources of digestible carbohydrates, minerals, antioxidants, fiber, and vitamins, particularly vitamin $\mathrm{A}, \mathrm{C}$ and $\mathrm{E}$ which are balanced nutritious diet for human beings [1], [2]. Chili peppers are widely cultivated in Ethiopia for their utilization of stew preparation to be consumed with Ethiopian traditional stippled food (thin-layer bread, injira) made from cereal grain especially teff (Eragrostis tef). Moreover, it is an essential constituent of Ethiopian curry due to its good color and pungency. It is indispensable in every household kitchen of Ethiopian societies throughout the year for everyday cooking and found in the form of green being consumed as salad and dried form called as berbere used for stew making and as flavoring agent. 
Chili peppers are also an important source of revenue in Ethiopia since its demand is very high in the international market.

According to the CSA, 453,608.8 ha of land is under vegetable in Ethiopia with annual production of $18,124,613.5$ quintal and among these production, red chili accounts about $70.89 \%$ [3]. However the post-harvest loss of red chili is very high and it is about $48 \%$ in Ethiopia[2].

Drying is one of the preservation mechanism of red chili. Red chili is traditionally dried directly under the open sun in Ethiopia. Open sun drying requires a large open space and long drying times. Although this traditional method requires only a small investment, open sun drying is highly dependent on the availability of sunshine and is susceptible to contamination from foreign materials (dust and sand) as well as insect and fungal infestations, which thrive in moist conditions. Such contaminations result aflatoxin formation caused by Asprigulus flavus fungus species in which the quality of the products significantly reduced. Therefore, solar cabinet drying has become one of the most attractive and promising applications of solar energy systems as an alternative to open sun drying in small scale drying system. However, the uniform distribution of drying parameters such as drying air, velocity and pressure through the solar cabinet dryer have a great impact on the quality of dried products. Drying is characterized as a combined multiscale, multiphysics and multiphase problem which is a very complex process. To describe explicitly this complex drying process, advanced mathematical modelling techniques like CFD, multiscale, multiphysics, and modelling of product properties and the associated spread of product property variability must be considered [4].The drying rate of any food product is highly depend on drying air properties, product characteristics, dryer design and operation procedure. However, it is very difficult, time taking and expensive to pinpoint the optimum drying parameters by using experimental measurements. Thus, to understand the dynamic and thermal behavior of the solar cabinet chili dryer, CFD modeling is very important. The CFD modeling implements influential computer and applied physics and mathematics to model the systems for the prediction of mass, heat and momentum transfer and to screen out the optimal design and operating conditions in chili drying process [5].

The aims of this study are to investigate the hydrodynamic and thermal performance of red chili solar cabinet dryer in terms of the uniform distribution of drying air velocity, temperature and pressure. 


\section{Materials and Methods}

\subsection{Materials}

Chili pepper, fully maturated, Mereko Fana species, with moisture content of $80 \%$ (wb) was used for the modeling and simulation of solar cabinet dryer. Data logger and pyrometer were used to record the daily drying parameters.

\subsection{Methods}

CFD Modeling and simulation of the solar cabinet chili dryer

Model set up: The solar cabinet dryer geometrical set up is shown in Fig. 1. The solar cabinet drying system consists of a double-pass solar collector $(2 \mathrm{mx} 4 \mathrm{~m})$, a blower, and a flatbed drying chamber. The total area of the collector is $8 \mathrm{~m}^{2}$. The drying chamber is $1.5 \mathrm{~m}$ in length, $1.0 \mathrm{~m}$ in width, and $1.94 \mathrm{~m}$ in height. There are eight trays with a distance of $0.1 \mathrm{~m}$ between each tray. The drying system is classified as a forced convection indirect type and angle of inclination of the collector was set to $22^{\circ}$ and face to south. Blower is placed on the nozzle end to suck air. The red chili is considered as porous media which spread in each tray with $0.05 \mathrm{~m}$ thickness. The solar collector is a double pass and the upper channel depth is $0.09 \mathrm{~m}$, and the lower depth is $0.09 \mathrm{~m}$, in between a $0.02 \mathrm{~m}$ thick absorber is placed. The solar cabinet dryer was designed to hold $40 \mathrm{~kg}$ of red chili, which was divided and equally distributed on eight trays.

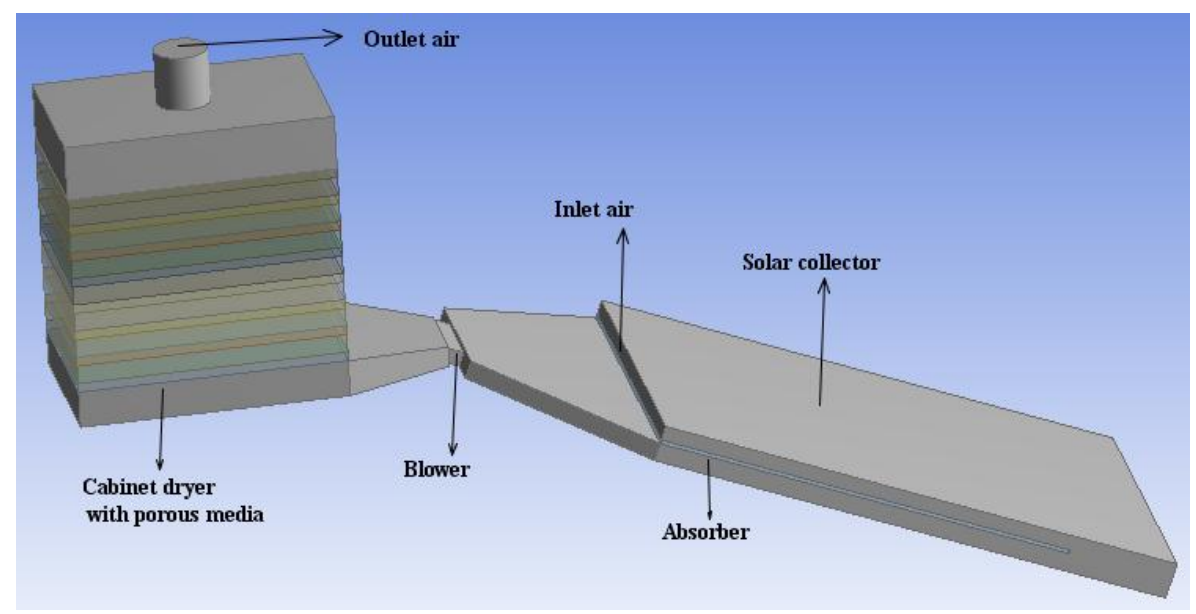

Fig. 1. Schematic sketch of the solar cabinet red chili dryer 
Set up the governing equations: The continuity, momentum and energy equations are determined as follow [6], [7]:

Continuity equation- The continuity equation is given by:

$$
\frac{\partial \rho}{\partial t}+\nabla(\rho \vec{u})=0
$$

Where $\overrightarrow{\boldsymbol{u}}$ and $\rho$ are velocity and density of air respectively.

Navier-Stokes equation- The Navier Stokes equation is given by [7]:

$$
\frac{\partial(\rho \vec{u})}{\partial t}+\nabla \cdot(\rho \vec{u} \vec{u})=-\nabla P+\nabla \overline{\bar{\tau}}+\rho \vec{g}+S_{m}
$$

Where $\overline{\bar{\tau}}$ and $S_{m}$ are Reynolds shear stress and momentum source term respectively.

Energy equation- The energy equation is given by:

$$
\frac{\partial(\rho E)}{\partial t}+\nabla \cdot(\vec{u}(\rho E+P))=\nabla \cdot(-\vec{q}+\overline{\bar{\tau}} \cdot \vec{u})+S_{h}
$$

Where, $S_{h}, \vec{q}$ and E are heat source term, heat flux vector and total energy respectively. The total energy (E) is the sum of internal energy and kinetic energy which is given by

$$
E=h-\frac{P}{\rho}+\frac{u^{2}}{2}
$$

where, $\mathrm{h}$ is the sensible enthalpy of air.

Turbulent model- The K- $\varepsilon$ turbulence model was used for this study and this model considered the conservation of turbulence kinetic energy, $\mathrm{k}$ and its corresponding dissipation rate, $\varepsilon$ through the following expression [8]:

$$
\frac{\partial(\rho k)}{\partial t}+\nabla \cdot(\rho \vec{u} k)=\nabla \cdot\left[\left(\mu+\frac{\mu_{t}}{\sigma_{k}}\right) \nabla k\right]+P_{k}-\rho \varepsilon
$$




$$
\frac{\partial(\rho \varepsilon)}{\partial t}+\nabla \cdot(\rho \vec{u} \varepsilon)=\nabla \cdot\left[\left(\mu+\frac{\mu_{t}}{\sigma_{\varepsilon}}\right) \nabla \varepsilon\right]+\frac{\varepsilon}{k}\left(C_{\varepsilon 1} P_{k}-C_{\varepsilon 2} \rho \varepsilon\right)
$$

Where, $C_{\varepsilon 1}, C_{\varepsilon 2}, \sigma_{k}$ and $\sigma_{\varepsilon}$ constants given as $1.44,1.92,1.0$ and 1.3 respectively for most computations.

Moisture transport: Water vapor is considered as a scalar property that does not influence the solutions of continuity, momentum and energy equations. Consequently, the transport of the scalar property is solved in autonomously as [6]:

$$
\frac{\partial(\rho w)}{\partial t}=\nabla \cdot(\rho \vec{v} w)=\nabla \cdot(\rho D)+S_{W}
$$

where $\mathrm{w}$ is ratio of humidity ( $\mathrm{kg}$ water vapor/kg dry air). $\mathrm{D}$ is the diffusion coefficient of water vapor and $S_{w}$ is the source term. Moisture transfer from the surface of the product to the environment (moisture source term, $S_{w}$ ) is governed by the following equation.

$$
M_{w}=h_{m} A_{s}\left(C_{S}-C_{\infty}\right)
$$

Where,

$$
\begin{gathered}
\mathrm{C}_{\mathrm{s}}=\frac{\mathrm{P}_{\text {sat }}}{\mathrm{RT}} \\
C_{\infty}=\mathrm{P}_{\text {sat }} * \mathrm{Rh} \\
\mathrm{P}_{\mathrm{Sat}}=\exp \left(65.8\left(\frac{7066.3}{\mathrm{~T}}\right)-5.98 \ln \mathrm{T}\right)
\end{gathered}
$$

$\mathrm{H}_{\mathrm{m}}$ is mass transfer coefficient and found from Nusselt number, 


$$
\mathrm{h}_{\mathrm{m}}=\frac{\mathrm{D}_{\mathrm{m}}}{\mathrm{d}_{\mathrm{p}}} \operatorname{Sch}
$$

$D_{m}$ is molecular diffusion coefficient of vapor in the gas, $d_{p}$ is chili diameter and Sch is the Sherwood number and $\mathrm{Rh}$ is relative humidity and As is specific surface area.

$$
\mathrm{D}_{\mathrm{m}}=104.91143 * 10^{-6} \frac{\mathrm{T}^{1.774}}{\mathrm{P}}
$$

The heat source term is also given as [9]:

$$
S_{h}=\rho \frac{\partial M}{\partial t} \mathrm{~L}_{v}
$$

where $L_{v}$ is the latent heat of vaporization of water from chili.

Moisture content and concentration: It is also clear that, in wet bases, moisture content is given by

$$
\mathrm{X}_{\mathrm{C}}=\frac{\mathrm{m}_{\mathrm{w}}}{\mathrm{m}_{\text {chili }}}=\frac{\mathrm{m}_{\mathrm{w}}}{\rho^{*} \mathrm{~V}}
$$

But, $\mathrm{m}_{\mathrm{w}}=\mathrm{nM}$ and the parameter, $\mathrm{n} / \mathrm{V}$, is the concentration. Therefore, from eqn.14, the concentration is determined as:

$$
\text { Conc }=\frac{X_{c}^{*} \rho_{\text {chili }}}{18^{*} 10^{\wedge}-3}
$$

where, $\mathrm{p}_{\text {chili }}$ is bulk density of chili $\left(500 \mathrm{~kg} / \mathrm{m}^{3}\right)$ [10], $\mathrm{M}$ is molecular mass of water, $\mathrm{m}_{\mathrm{w}}$ is sample mass of chili and $\mathrm{n}$ is mole of sample mass. Initial moisture content (Xc) of chili is about $80 \%$ and final allowable moisture content of chili is about $5-12 \%$. The environmental conditions of Bahir Dar city have been taken for the simulation process. Radiation was modelled using Monte carlo radiation model.

Porous media modeling: The red chili is considered as porous media in the solar cabinet dryer. The porous media is modelled by the addition of a momentum source term to the standard fluid flow equations such as conservation of energy, momentum and 
moisture transport equation. In the momentum equation, the two losses such as inertial losses and viscous losses are found as source term and expressed as [6], [11]:

$$
\frac{\partial P}{\partial z}=-\left(\frac{\mu}{\alpha}\right) u_{z}+C \frac{1}{2} \rho u_{z}^{2}
$$

where $\mathrm{C}$ is the inertial loss coefficient and $(1 / \alpha)$ is the viscous loss coefficient. Ergun [12] developed an equation for packed beds which has been applied successfully for porous media.

$$
\frac{\Delta P}{L}=\frac{150 \mu\left(1-\varepsilon^{2}\right)}{d_{p}^{2} \varepsilon^{3}} u+\frac{1.75 \rho(1-\varepsilon)}{d_{p}(1-\varepsilon)} u^{2}
$$

For this simulation study, the chili porosity was assumed to be constant at 0.4 and chili particle diameter $\left(\mathrm{d}_{\mathrm{p}}\right)$ of $0.064 \mathrm{~cm}$ at $80 \%$ moisture content.

CFD model solution procedures- The hydrodynamic solar cabinet chili dryer model was discretized with finite volume method and simulated using ANSYS- CFX software.

\section{Initial and boundary conditions}

Initial condition- The fluid in the solar tunnel chili dryer is initially assumed stagnant and at a uniform ambient temperature of $25^{\circ} \mathrm{C}$.

Boundary conditions-Walls: A no slip wall condition was used.

Inlet- The optimum inlet drying air velocity was set at $1.5 \mathrm{~m} / \mathrm{s}$, and the turbulence intensity was set at 5\%. The inlet temperature was varied throughout the drying time and expressed as:

$$
\mathrm{T}=-4 \mathrm{e}-8 * \mathrm{t}^{2}+0.0012 * t+19.38
$$

The radiation intensity and relative humidity were also varied and the average daily solar intensity and relative humidity were $500 \mathrm{~W} / \mathrm{m}^{2}$ and $45 \%$ respectively.

Outlet- Gauge pressure $=0$

For the solar collector Monte carlo radiation boundary was considered. The emissivity and diffuse fraction of the collector was 0.9 and 0.05 respectively. 


\section{Results and discussions}

\subsection{Mesh generation and analysis}

The mesh/grid of the model is shown in Fig.2. The mesh was generated based on medium relevance center and has 15179 nods and 53053 elements. The grid was refined to confirm mesh independence. When the percentage different between the two successive meshes is negligible, it is possible to say there is mesh independency. To identify mesh independency, the simulation was proceeded from coarse to fine mesh and the variation of the desired simulation output was checked. It is also possible to have mesh independent solution by using a very fine uniform mesh. However, it would take days/months to end the simulation process and thus, the simulation of this study was conducted on medium mesh.

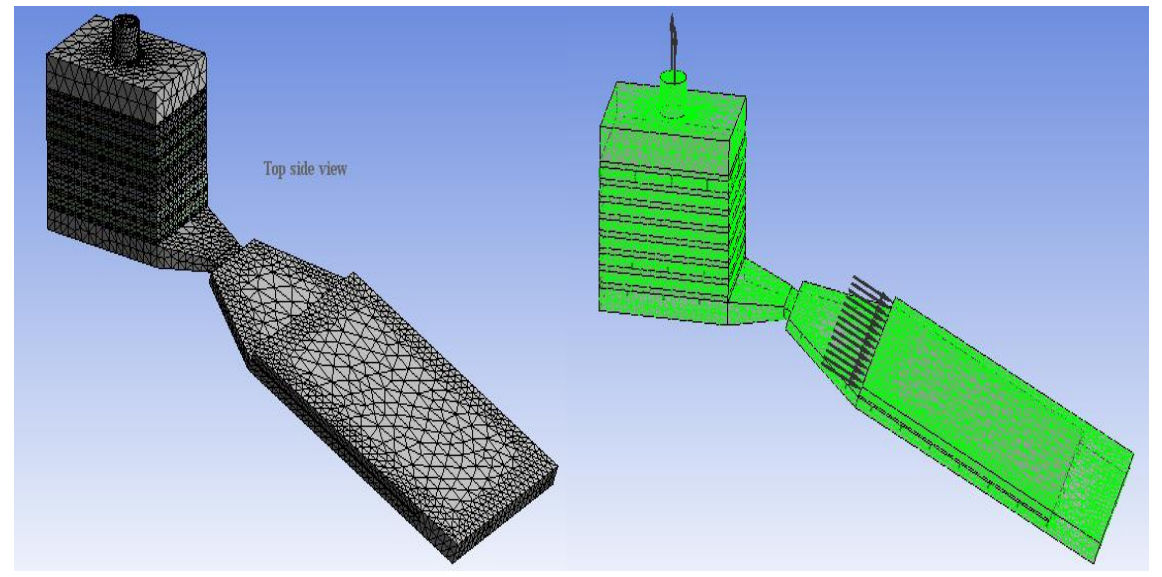

Fig.2. The mesh/grid generation of the model

\subsection{Drying air velocity distribution}

The velocity contour inside the drying chamber is shown in Fig.3. As it can be seen in this figure, it was observed that a uniform velocity distribution throughout the drying chamber (at maximum velocity of $1.5 \mathrm{~m} / \mathrm{s}$ ) was prevailed. On the other hand, relatively high velocity was achieved at the inlet and outlet of the dryer. This may be due to small cross section in the specified area. 


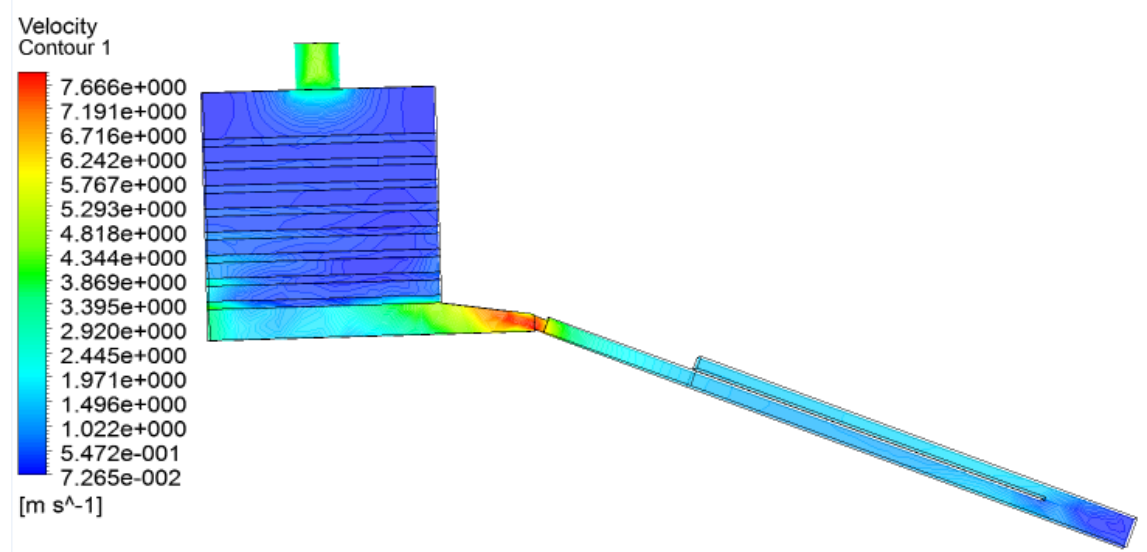

Fig.3. Velocity contour of the drying chamber

The velocity streamline is also presented in Fig.4. From this figure, it was clearly seen that the solar cabinet dryer has good air distribution in solar collector and porous region which in turn will have huge positive impact on the product quality at the end.
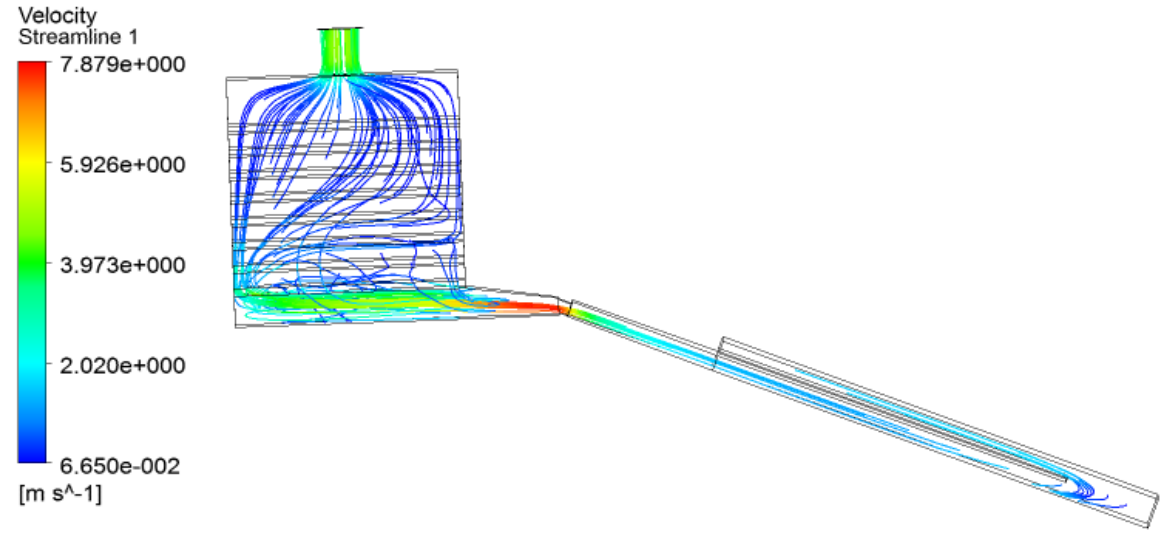

Fig.4. Velocity streamline of the chili drying chamber

\subsection{Drying temperature distribution}

The double pass solar collector is very important to enhance temperature that required to heat the drying air. The temperature profile of solar absorber is shown in Fig.5. As it can be seen from this figure, at the inlet of the absorber, the temperature was low, however, at the outlet of the absorber, high temperature was noticed. The maximum temperature of the absorber was about $54^{\circ} \mathrm{C}$ which is enough to heat the prevailing 
drying air and it is an indication that double pass solar collector enhanced the performance of the solar cabinet chili dryer.
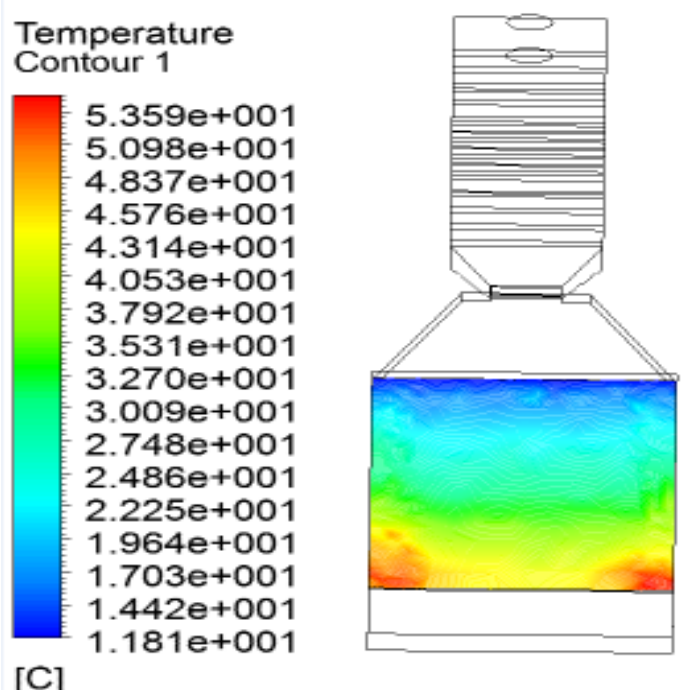

Fig.5. Solar absorber temperature profile with double pass solar collector

This magnitude of temperature $\left(54^{\circ} \mathrm{C}\right)$ was utilized to heat the drying air throughout the drying chamber and hence the overall temperature profile of the solar cabinet drying system is presented in Fig.6. It was observed that the temperature was reduced from 54 to $43^{\circ} \mathrm{C}$ during chili drying process due to moisture removal.
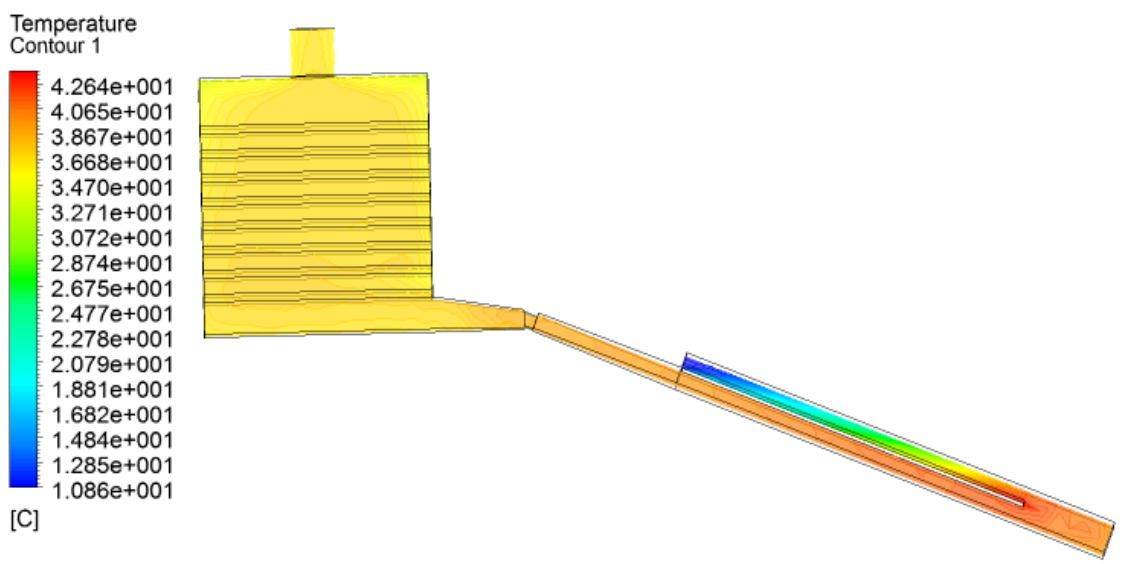

Fig.6. Temperature profile of the solar cabinet chili drying system 
The final utilized temperature in the porous media (chili) drying is very important. More specifically, the temperature profile of only porous media is shown in Fig.7. As it can be seen in Fig.7, the temperature profile of the porous media (red chili per tray) was in the range of $36-39.7^{\circ} \mathrm{C}$. Ahmad Fudholi et al. [13] were studied experimentally, solar cabinet chili dryer and the temperature was in the range of $28-55^{\circ} \mathrm{C}$ which indicated that there was some similarity of the thermal performance to this simulation study.

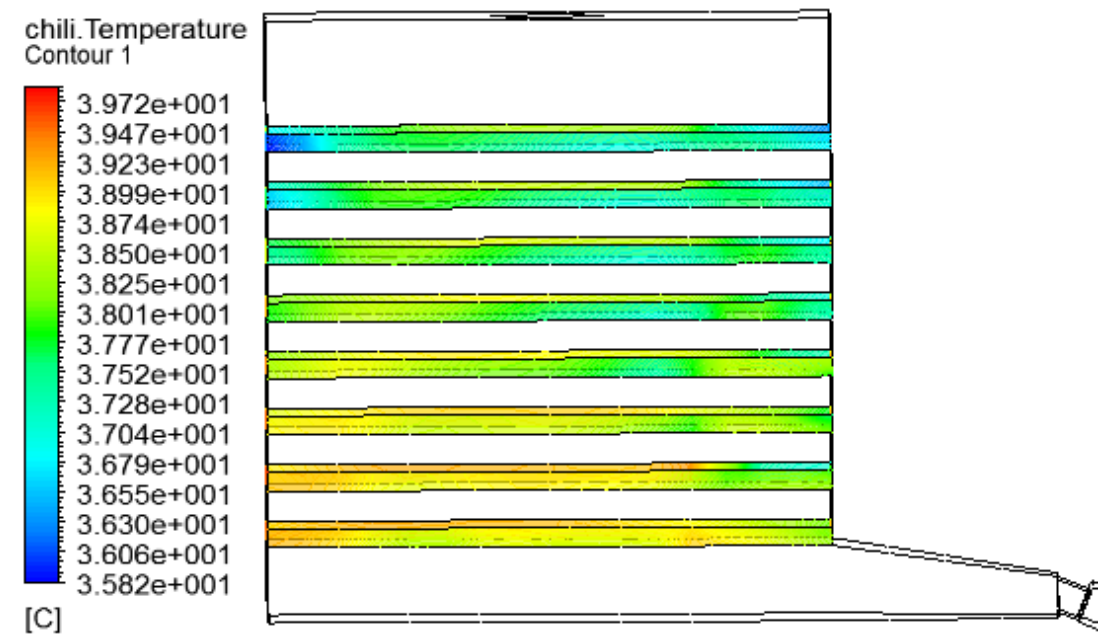

Fig.7. Porous media temperature profile

Inside the solar cabinet chili dryer chamber there are eight porous media/tray/ placed at $0.1 \mathrm{~m}$ distance from the bottom to top of the dryer. At the beginning of drying process, the obtained energy serves only to evaporate water from the product. After that, the obtained energy serves, in the one hand, to evaporate the water of the product and, on the other hand, to increase the temperature of the media. The convective effect also increased the temperature in the first tray, thus due to these direct heating and convective heat transfer, evaporation of water was higher in the first, second and the third tray than the other trays. However, this is not the case for the next porous, where the obtained energy only serves to water evaporation and the convective heat transfer resulted saturation of the evaporated water due to accumulation of the evaporated water from the preceding layers. Similar study was conducted by Belhamri et al.[14].

High temperature was observed at the center of the dryer and to some extent low near to the corner of the dryer. Moreover, as it can be seen in Fig.7, temperatures of the porous media were decreased starting from the third porous media to the last porous 
media due to moisture removal that reduced the next porous media temperature and it has been clearly identified through graphical representation as shown in Fig.8.

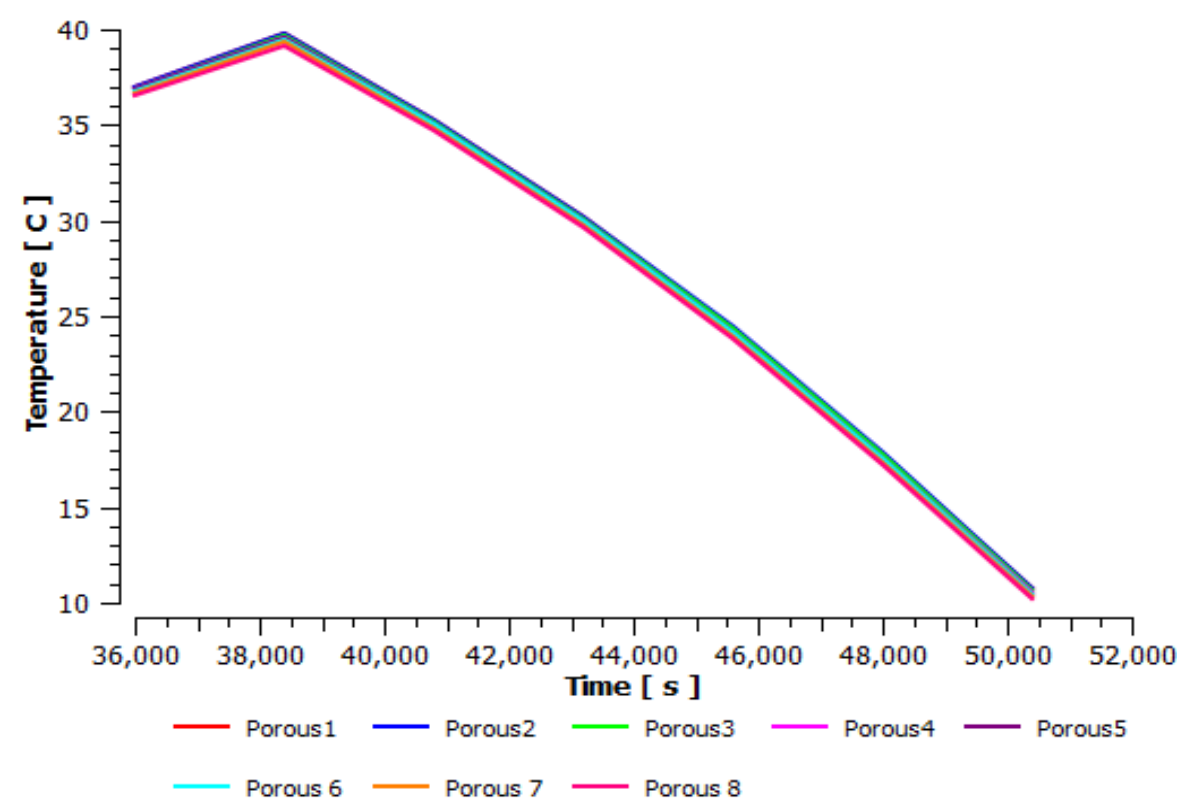

Fig.8. Porous media temperature profile per each tray

In the start of drying time temperature was dramatically increased and as the drying time increased the temperature also decreased as shown in Fig.8.

\subsection{Pressure drop across the porous media}

The pressure profile of solar cabinet red chili dryer is presented in Fig.9. As it can be seen in this figure, the drying chamber pressure drop in general increased throughout the drying chamber as drying time increased. It is may be due to shrinkage of porous medium during experiment as heat supplied, thus reducing its permeability which is the cause of pressure drop. However, from one porous to the other porous (staring from the bottom to the top of dryer, porous 1-porous 8), at a fixed time, the pressure drops were reduced due to the resistance of the porosity of the chili. 


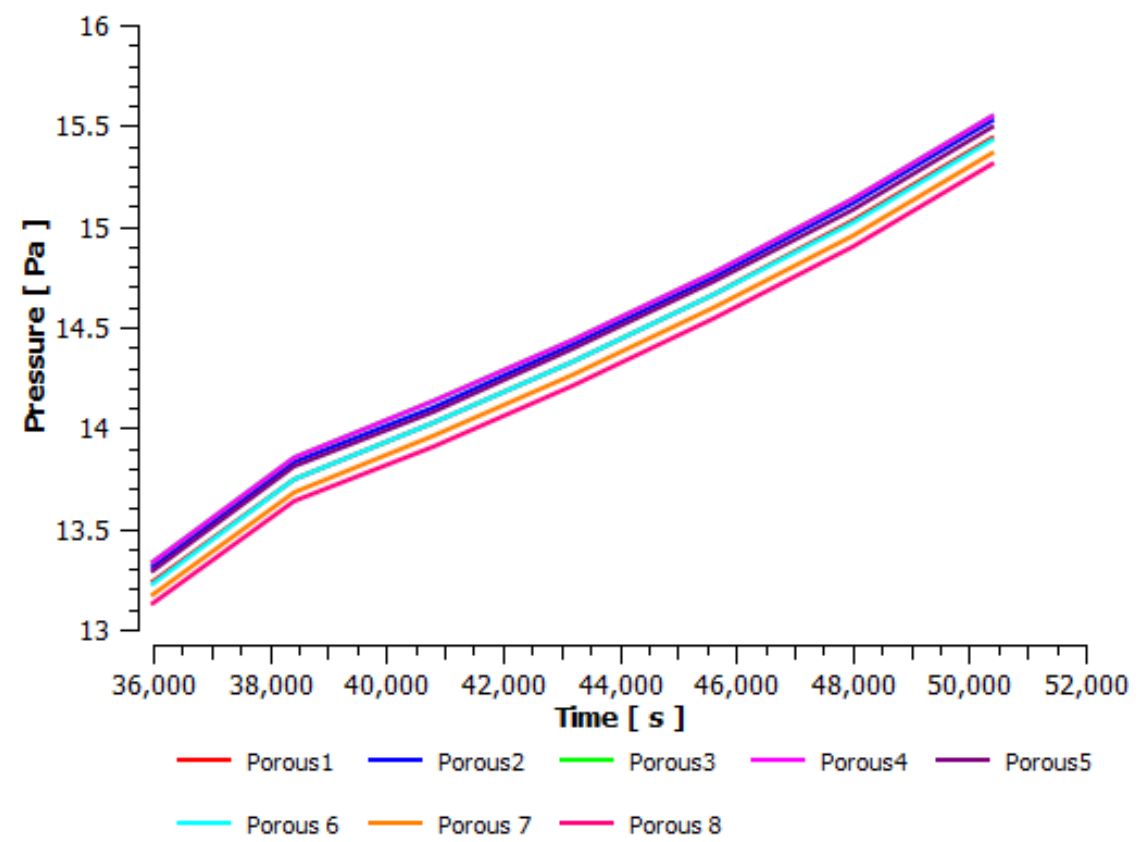

Fig.9. Pressure distribution of the solar cabinet red chili dryer

\subsection{Performance of the solar cabinet dryer}

Initially the drying rate was significantly high since evaporation took place near the surface of the chili and hence unbound water completely removed. As drying progressed, the drying rate decreased due to the reduction of moisture content. In this case, the moisture to be evaporated comes from internal cells within the structure (bound water) and must be transported to the surface in which highly resistive for mass and heat transfer.

The moisture content which was removed from the red chili by the heated air is shown in Fig. 10. As it can be seen in this figure, the inlet air has low water vapor inside it. Moreover, the air is found at high level of temperature and the water vapor content was increased at the first parts of the porous media (product) since most of the surface water was removed and moved with the air. Water removal reduced from the first porous to the last porous media due to reduction in temperature along the vertical distance of the solar cabinet chili dryer. 


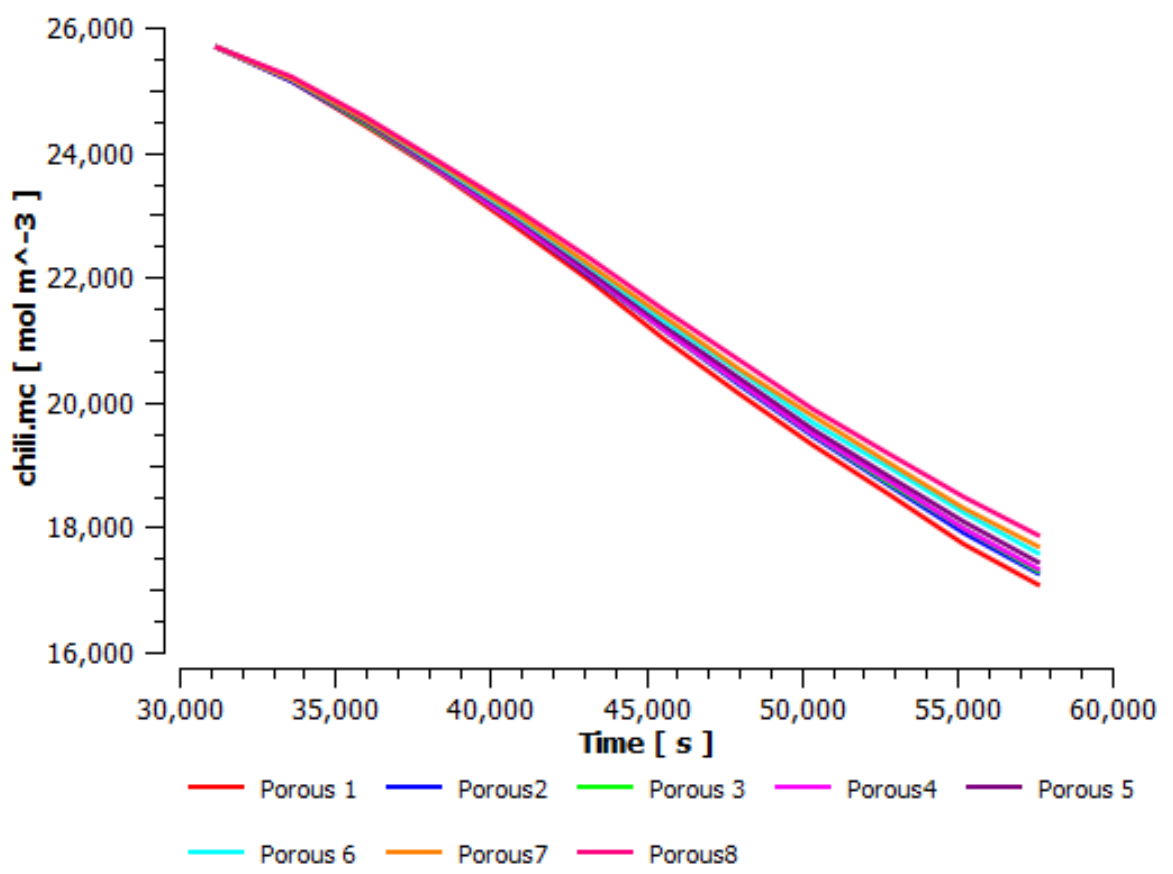

Fig.10. Volumetric average chili moisture content profile per tray (wet basis)

Even though the moisture removal performance of the solar cabinet chili dryer was found in a promising trend, it was not sufficiently stabilized the removal of moisture content in the porous media due to the short simulation (drying) time. It reduced the moisture content form the initial value of $80 \%$ to $49 \%$ in wet bases within $16 \mathrm{hrs}$.

\section{Conclusions and Recommendations}

In this modeling and simulation, the drying temperature and velocity were found uniform throughout the solar cabinet dryer. The solar absorber temperature was $54^{\circ} \mathrm{C}$ and the drying chamber temperature was found in the range of $36-39.7^{\circ} \mathrm{C}$. The moisture was reduced from $80 \%$ to $49 \%$ in wet bases within 16 hrs. Generally the modeling and simulation result showed that the performance of the solar cabinet red chili dryer was very promising one. Further optimization of drying temperature, velocity distribution is very essential through fully converged iteration process and it is under progress. The high performance computer will be also mandatory to analyze the whole drying process. 


\section{Acknowledgement}

The research fund was granted from Bahir Dar Energy Center, Bahir Dar Institute of technology, Bahir Dar University, Ethiopia

\section{References}

[1] T. Demissie, A. Ali, and D. Zerfu, "Availability and consumption of fruits and vegetables in nine regions of Ethiopia with special emphasis to vitamin A deficiency," Ethiop. J. Heal. Dev., 2010.

[2] G. Hailu and B. Derbew, "Extent, causes and reduction strategies of postharvest losses of fresh fruits and vegetables - A review," J. Biol. Agric. Healthc., no. 5, pp. 49-64, 2015.

[3] C. S. A. (CSA) (2015/2016)., “Agricultural Sample Survey 2015/2016, Vol. 1, Report on Area and Production of Major Crops, Addis Ababa.," Re, 2016.

[4] T. Defraeye, "Advanced computational modelling for drying processes - A review," Applied Energy, vol. 131. pp. 323-344, 2014.

[5] B. Xia and D.-W. Sun, "Applications of computational fluid dynamics (CFD) in the food industry: a review," Comput. Electron. Agric., vol. 34, pp. 5-24, 2002.

[6] A. Sanghi, R. P. K. Ambrose, and D. Maier, "CFD simulation of corn drying in a natural convection solar dryer," Dry. Technol., vol. 36, no. 7, pp. 859-870, 2018.

[7] P. Demissie, M. Hayelom, A. Kassaye, A. Hailesilassie, M. Gebrehiwot, and M. Vanierschot, "Design, development and CFD modeling of indirect solar food dryer," in Energy Procedia, 2019.

[8] J. Aukah and M. Muvengei, "Simulation of Drying Uniformity inside Hybrid Solar Biomass Dryer using ANSYS CFX,” ... Sustain. Res. ..., pp. 336-344, 2015.

[9] P. M. Cârlescu, V. Arsenoaia, R. Roşca, and I. țenu, "CFD simulation of heat and mass transfer during apricots drying," LWT - Food Sci. Technol., vol. 85, pp. 479-486, 2017.

[10] U. R. Charrondiere, D. Haytowitz, and B. Stadlmayr, "FAO/ INFOODS Databases: Density Database Version 2.0," Database, 2012. .

[11] P. D. Tegenaw, M. G. Gebrehiwot, and M. Vanierschot, "On the comparison between computational fluid dynamics (CFD) and lumped capacitance modeling for the simulation of transient heat transfer in solar dryers," Sol. Energy, 2019.

[12] S. Ergun, "Fluid flow through packed columns," Chem. Eng. Prog., 1952.

[13] A. Fudholi, K. Sopian, M. H. Yazdi, M. H. Ruslan, M. Gabbasa, and H. A. Kazem, "Performance analysis of solar drying system for red chili," Sol. Energy, vol. 99, pp. 47-54, 2014.

[14] L. Bennamoun and A. Belhamri, "Study of heat and mass transfer in porous media: Application to packed-bed drying," Fdmp, vol. 4, no. 4, pp. 221-230, 2008. 